\title{
Controle de Plantas daninhas em Milho em Função de Quantidades de Palha de Nabo ForRageiro ${ }^{1}$
}

\author{
Weed Control in Corn as a Function of Amount of Turnip Crop Residue
}

RIZZARDI, M.A. ${ }^{2}$, SILVA, L.F. ${ }^{3}$ e VARGAS, L. ${ }^{4}$

\begin{abstract}
RESUMO - Objetivou-se com este experimento avaliar a influência da quantidade de palha de nabo forrageiro (Raphanus sativus var. oleiferus) no controle de plantas daninhas em milho. $\mathrm{O}$ delineamento experimental foi o de parcelas subdivididas, em blocos casualizados, com quatro repetições. Os tratamentos constaram das quantidades de 0,6 e $9 \mathrm{t} \mathrm{ha}^{-1}$ de palha de nabo forrageiro, além do pousio, dispostas na parcela principal e, ainda, de seis momentos de controle de plantas daninhas (milho com 1, 2, 4, 5, 6 e 7 folhas), mais duas testemunhas (sem a presença de plantas daninhas e sem o controle destas), dispostos nas subparcelas. Houve interação de quantidades de palha e momentos de controle em relação ao grau de controle de plantas daninhas; o melhor momento ocorreu entre os estádios de duas a quatro folhas do milho. Na ausência de controle químico, o rendimento de grãos de milho foi superior no tratamento com $9 \mathrm{t} \mathrm{ha}^{-1} \mathrm{de}$ palha de nabo forrageiro. O controle químico não proporcionou aumento significativo no rendimento de grãos do milho quando a quantidade de palha de nabo forrageiro foi de $9 \mathrm{t} \mathrm{ha}^{-1}$.
\end{abstract}

Palavras-chave: interferência, cobertura vegetal, herbicidas.

ABSTRACT - The objective of this study was to evaluate the effect of the amount of turnip (Raphanus sativus var. oleiferus) crop residue on weed control in corn. The experimental design was a split-plot, in randomized blocks, with four replications. The treatments tested were 0,6 , and $9 \mathrm{t} \mathrm{ha} \mathrm{a}^{-1}$ of turnip crop residues, fallow period (the amount of residues was equivalent to the amount of natural vegetation residues), arranged as main plots, and six weed control periods (corn plants with 1, 2, 4, 5, 6, and 7 developed leaves), besides two controls (one without weeds and another without weed control), arranged as subplots. Interactions occurred between residue amounts and control periods in relation to the degree of weed control. The best control period was achieved when the corn plants presented from 2 to 4 developed leaves. Corn grain yield was higher in the control plots with no weed control than in the plots with 9 tha $a^{-1}$ of turnip crop. Chemical control did not increase corn grain yield, when the amount of turnip crop was 9 t ha ${ }^{-1}$.

Keywords: interference, plant cover, herbicide.

\section{INTRODUÇÃO}

No sistema de semeadura direta, a cobertura vegetal formada pela cultura anterior provoca efeitos físicos, afetando a germinação e a taxa de sobrevivência das plântulas de diferentes espécies (Pereira \& Scheeren, 2002).
Além de alterar a umidade, a luminosidade e a temperatura do solo, que são as principais variáveis no controle da dormência e germinação das sementes, a cobertura pode interferir no desenvolvimento das plantas, causando o estiolamento e tornando-as suscetíveis aos danos mecânicos. A cobertura vegetal pode

Recebido para publicação em 29.11.2005 e na forma revisada em 5.5.2006.

2 Eng.-Agr., D.S., Professor da Faculdade de Agronomia e Medicina Veterinária da Universidade de Passo Fundo (FAMV/UPF), Caixa Postal 611, 99001-970 Passo Fundo-RS, <rizzardi@ upf.br, Bolsista CNPq>. ${ }^{3}$ Mestranda do Programa de Pós-graduação em Agronomia da FAMV/UPF. ${ }^{4}$ Eng.-Agr., D.S., Pesquisador da Embrapa Trigo, <vargas@ cnpt.embrapa.br>.

Planta Daninha, Viçosa-MG, v. 24, n. 2, p. 263-270, 2006 
proporcionar ainda ações químicas decorrentes de mudanças nas relações $\mathrm{C} / \mathrm{N}$ ou de alelopatia (Pereira \& Scheeren, 2002).

Diversos autores destacam que as plantas que se estabelecem primeiro adquirem vantagem na competição (Fleck et al., 2002). O controle na fase inicial do desenvolvimento da planta daninha é importante, e sementes de plantas daninhas que emergem mais tarde, quando a cultura já está estabelecida, não resultam em perdas significativas no rendimento do milho (Knezevic et al., 1994).

Portanto, deve-se lançar mão de todos os artifícios que possam resultar no atraso da emergência das plantas daninhas, entre eles a utilização racional da cobertura vegetal do solo, formada a partir dos resíduos deixados pela cultura anterior. Dessa forma, quanto maior a quantidade de palha disponível, maior será o tempo em que a cultura permanece sem a interferência, podendo-se talvez atrasar o momento de controle das plantas daninhas ou até mesmo, em função da quantidade de palha, suprimi-lo. Contudo, as interações que ocorrem no ecossistema agrícola são muito específicas e dinâmicas, dependendo da quantidade de palha e, principalmente, da espécie de planta daninha que pode ser favorecida ou não pela cobertura vegetal (Correia \& Durigan, 2002).

O sucesso do uso de herbicidas pós-emergentes depende da capacidade do produtor em determinar o momento correto de aplicação do produto para controlar as plantas daninhas. Com o atraso na aplicação desses herbicidas há menor eficácia de controle, pelo fato de as plantas apresentarem maior desenvolvimento vegetativo; com isso, elas adquirem maior tolerância aos herbicidas. Por outro lado, as aplicações de herbicidas realizadas precocemente proporcionam melhor controle, porém pode ocorrer novo fluxo de emergência, influenciando negativamente o rendimento da cultura (Fleck et al., 2002).

Portanto, o objetivo deste trabalho foi avaliar a influência da quantidade de palha de nabo forrageiro (Raphanus sativus var. oleiferus) no controle de plantas daninhas em milho.

\section{MATERIAL E MÉTODOS}

O experimento foi conduzido na área experimental de herbologia da Faculdade de
Agronomia e Medicina Veterinária da Universidade de Passo Fundo, em Passo Fundo - RS. O delineamento experimental utilizado foi o de blocos casualizados, com os tratamentos dispostos em parcelas subdivididas. As parcelas principais constituíram-se das quantidades de palha produzidas pela cobertura de nabo forrageiro, e as subparcelas, dos momentos de controle das plantas daninhas no milho. Foram utilizadas quatro repetições, totalizando 128 unidades experimentais, com área de $15,0 \mathrm{~m}^{2}$ cada uma $(3,0 \times 5,0 \mathrm{~m})$. As subparcelas foram compostas por quatro linhas de milho.

Os tratamentos constaram de coberturas vegetais formadas por três quantidades de palha de nabo forrageiro $\left(0,6\right.$ e $\left.9 \mathrm{t} \mathrm{ha}^{-1}\right)$ e pelo pousio $\left(2 \mathrm{t} \mathrm{ha}^{-1}\right)$, constituído pela presença de plantas daninhas que emergiram espontaneamente na área, e, ainda, de momentos de controle das plantas daninhas. O fator controle foi composto de seis momentos: $5,11,19,28$, 33 e 40 dias após a emergência do milho - DAE, além de duas testemunhas (com e sem controle total das plantas daninhas). Nos momentos de controle, as plantas de milho se encontravam nos estádios de 1, 2, 4, 5, 6 e 7 folhas, ou seja, $5,11,19,28,33$ e $40 \mathrm{DAE}$, respectivamente.

A semeadura do nabo forrageiro foi feita de forma mecanizada, sendo a semeadora regulada para distribuir $32 \mathrm{~kg} \mathrm{ha}^{-1}$ de semente. A adubação utilizada foi de $150 \mathrm{~kg} \mathrm{ha}^{-1} \mathrm{da}$ fórmula 05-25-25, conforme a análise química do solo, a qual indicou a presença de $490 \mathrm{~g}$ de argila por kg de solo; $\mathrm{pH}$ (em água) de 5,7; $28 \mathrm{mg}$ de $\mathrm{P}_{2} \mathrm{O}_{5} \mathrm{~L}^{-1} ; 182 \mathrm{mg}$ de $\mathrm{K}_{2} \mathrm{O}$ por $\mathrm{L}^{-1}$; e $2,4 \mathrm{~g}$ de matéria orgânica por $\mathrm{kg}$ de solo. As parcelas sob pousio receberam somente a adubação, não sendo realizada a semeadura do nabo forrageiro.

O manejo químico do nabo forrageiro e da área sob pousio foi realizado 12 dias antes da semeadura do milho, mediante a aplicação de paraquat (Gramoxone a 2,0 L ha'-1), utilizando-se volume de calda de $200 \mathrm{~L} \mathrm{ha}^{-1}$. Um dia após o manejo químico, foi realizado o corte das coberturas com roçadora, a fim de permitir a transferência da palha do tratamento sem palha na superfície para a área do tratamento com $9 \mathrm{t} \mathrm{ha}^{-1}$, sendo este realizado manualmente. Salienta-se que o tratamento denominado sem palha permaneceu com as raízes do nabo forrageiro. 
O presente experimento foi instalado em área com infestação mista de plantas daninhas, com predominância de Brachiaria plantaginea (papuã) e de infestação mista de Bidens pilosa $e$ B. subalternans (picão-preto).

O milho, cultivar DKB $909 \mathrm{CL}$, foi semeado mecanicamente, em espaçamento de 0,7 m entre linhas, na densidade de 70.000 plantas ha-1 ${ }^{-1}$ Antecedendo a semeadura do milho, efetuou-se o tratamento de sementes com carboxin + thiram (200 g de Vitavax + Thiram $100 \mathrm{~kg}$ sementes ${ }^{-1}$ ). A adubação do solo foi realizada nas linhas de semeadura, utilizando-se $350 \mathrm{~kg} \mathrm{ha}^{-1}$ da fórmula 05-25-25. Foi efetuada uma única adubação nitrogenada em cobertura (150 kg ha-1 de N), quando o milho apresentava seis folhas desenvolvidas.

Nas parcelas em que se efetuou o controle das plantas daninhas, realizado em área total e em pós-emergência, utilizou-se o herbicida imazapic + imazapyr (Onduty a $100 \mathrm{~g} \mathrm{ha}^{-1}$ ), acrescido de adjuvante não-iônico (Dash $0,15 \% \mathrm{v} \mathrm{v}^{-1}$ ). Nas aplicações do herbicida, utilizou-se pulverizador costal de precisão, operado com pontas de pulverização de jato plano, série XR 110.03, à pressão constante de $200 \mathrm{kPa}$, distribuindo volume de calda equivalente a $200 \mathrm{~L} \mathrm{ha}^{-1}$.

A cada sete dias após a semeadura do milho e durante sete semanas foi avaliada a densidade de plantas daninhas, mediante a contagem numa área de $0,125 \mathrm{~m}^{2}$ por subparcela. No momento do florescimento realizou-se também a coleta das plantas daninhas, para identificação e determinação da biomassa seca.

As avaliações visuais de controle das plantas daninhas foram realizadas aos $7,14 \mathrm{e}$ 30 dias após a aplicação do herbicida - DAA. Para isso, utilizou-se escala percentual, em que a nota zero correspondeu a nenhum efeito de controle e a nota 100 significou morte completa das plantas daninhas.

O rendimento do milho foi determinado em área de 7,0 m² (1,4 x $5 \mathrm{~m})$, englobando as duas linhas centrais das subparcelas. Por ocasião da pesagem dos grãos foi determinada sua umidade, e, posteriormente, os pesos obtidos foram uniformizados para $13 \%$ de umidade.

Os dados coletados para as variáveis avaliadas foram submetidos à análise de variância pelo teste F. Havendo interação significativa entre quantidades de palha e momentos de controle das plantas daninhas $(\mathrm{P}<0,10)$, procedeu-se à análise de regressão. As regressões foram realizadas entre a variável-resposta e o momento de controle das plantas daninhas, utilizando-se modelo linear e quadrático para ajustar a distribuição dos dados obtidos. Já os dados percentuais de controle das plantas daninhas foram transformados para raiz quadrada de $(\mathrm{x}+1)$, para realização da análise de variância. Quando significativo o teste $F$ ( $\mathrm{p} \leq 0,05)$, foi feita a análise comparativa de médias pelo teste de Tukey a $5 \%$.

\section{RESULTADOS E DISCUSSÃO}

Nas avaliações de controle das plantas daninhas, obteve-se interação significativa de quantidades de palha e momentos de controle, tanto para papuã (Tabela 1) como para picãopreto (Tabela 2).

Na avaliação realizada aos 7 DAA do herbicida, o controle de papuã, nas quantidades de 0, 6 e $9 \mathrm{t} \mathrm{ha}^{-1}$ de palha de nabo forrageiro, foi semelhante entre os tratamentos, até as aplicações realizadas no estádio de quatro folhas do milho (Tabela 1). Já nos tratamentos que permaneceram sob pousio, antes da implantação da cultura, o controle foi o mesmo somente nas aplicações do herbicida até o estádio de duas folhas do milho. Aos 14 e 30 DAA do herbicida, observa-se que, nas coberturas de 6 e $9 \mathrm{t} \mathrm{ha}^{-1}$ de palha de nabo forrageiro, os melhores níveis de controle de papuã deram-se quando as aplicações foram realizadas até o estádio de cinco folhas do milho, não ocorrendo o mesmo nos tratamentos sem palha e sob pousio.

Em todas as coberturas, as aplicações realizadas quando o milho possuía mais de cinco folhas apresentaram menor eficicácia de controle de papuã. Essa observação pode ser devida ao fato de que, com o crescimento das plantas daninhas, a superfície foliar é revestida com camada cerosa mais espessa e com mais substâncias lipofillicas, dificultando a absorção do herbicida (Vidal, 2002). Além disso, plantas mais velhas são submetidas a maior diversidade de ambientes, tendo assim mais cutícula e, com composição mais complexa, aumentando a tortuosidade e dificultando a absorção do herbicida (Vidal, 2002). 
Tabela 1 - Porcentagem de controle de Brachiaria plantaginea (papua), com quantidades de palha e momentos diferentes de controle, avaliada aos 7, 14 e 30 DAA do herbicida. Cepagro/UPF, Passo Fundo-RS, 2002/03

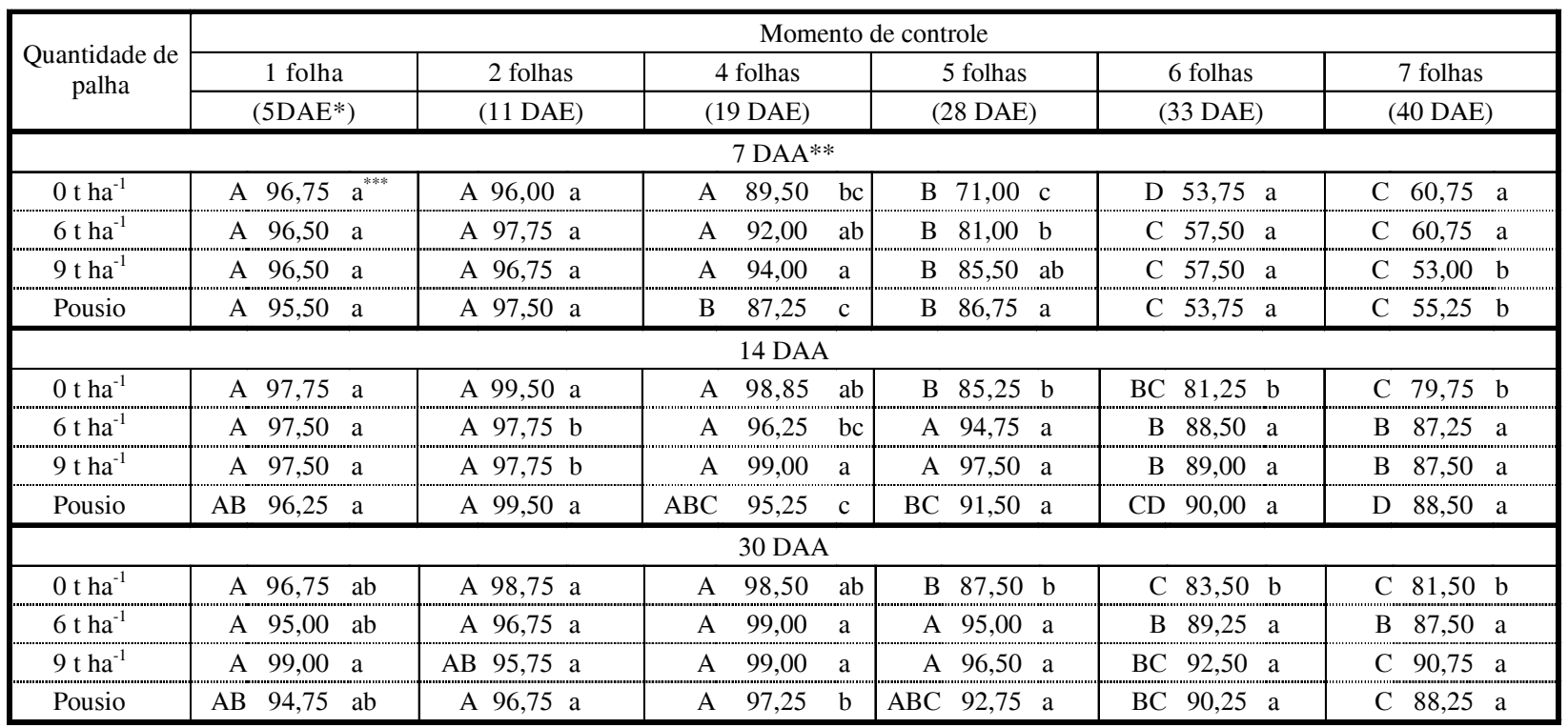

* DAE = dias após a emergência. **DAA = dias após a aplicação. *** Médias antecedidas da mesma letra maiúscula na linha, ou sucedidas da mesma letra minúscula na coluna, não diferem estatisticamente pelo teste de Tukey a $5 \%$ de probabilidade.

Tabela 2 - Porcentagem de controle de Bidens spp. (picão-preto), com quantidades de palha e em momentos diferentes de controle, avaliada aos 7, 14 e 30 DAA do herbicida. Cepagro/UPF, Passo Fundo-RS, 2002/03

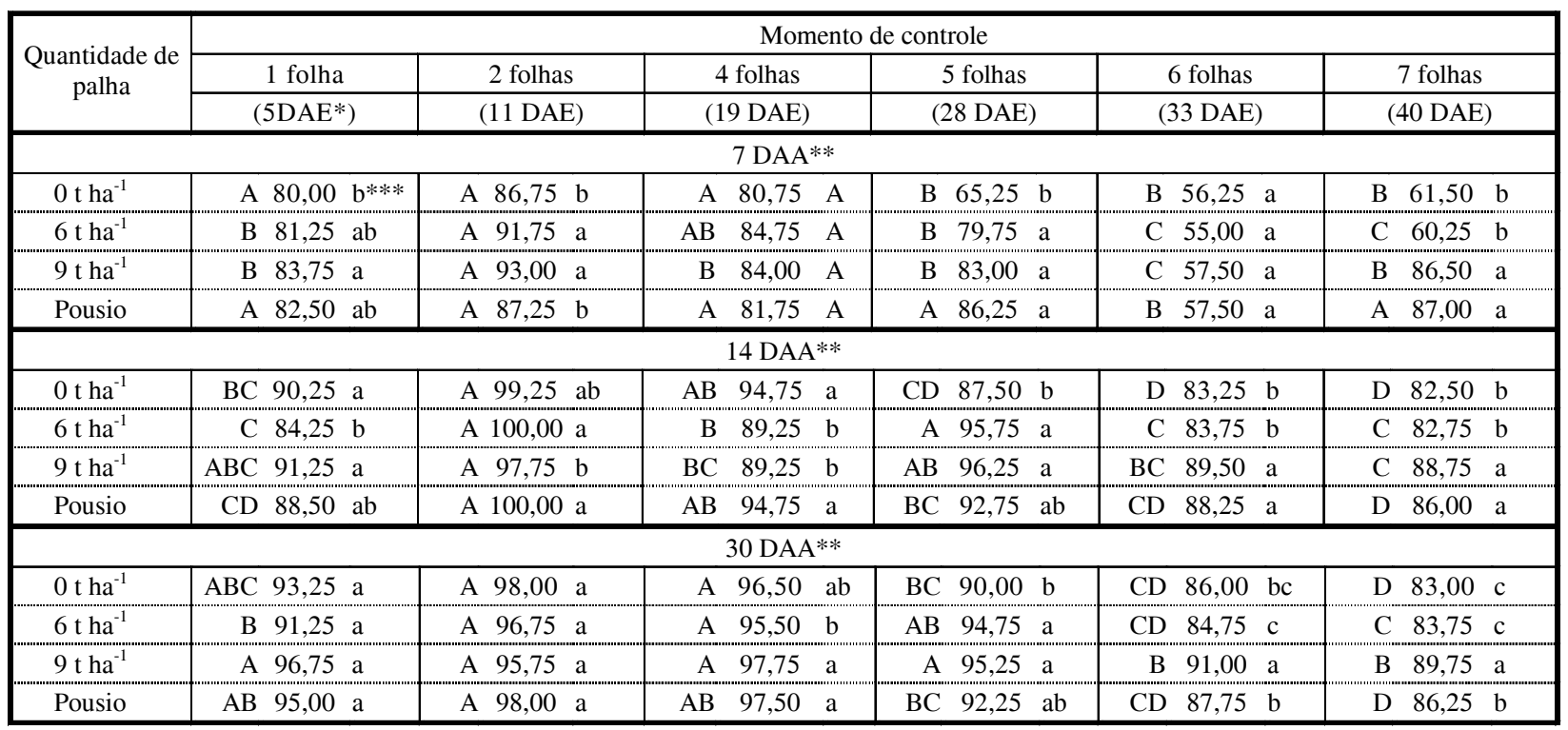

* DAE = dias após a emergência. **DAA = dias após a aplicação. *** Médias antecedidas da mesma letra maiúscula na linha, ou sucedidas da mesma letra minúscula na coluna, não diferem estatisticamente pelo teste de Tukey a $5 \%$ de probabilidade.

Quanto ao picão-preto, observou-se que o controle pode ser menos precoce que para papuã, especialmente quando na presença de cobertura vegetal, já que o controle realizado precocemente permitiu novo fluxo de emergência (Tabela 2). Esses resultados indicam, também, que nas doses em que o herbicida foi utilizado não há efeito residual no solo. As 
avaliações demonstraram que o controle realizado quando o milho apresentava somente uma folha foi inferior ao realizado quando este estava com duas folhas. O controle mais eficaz foi com o milho no estádio de duas folhas, em todas as quantidades de palha, exceto com $9 \mathrm{t} \mathrm{ha}^{-1}$, quando a avaliação foi feita aos 30 DAA do herbicida. Nas parcelas sem cobertura de palha, os controles no estádio de cinco folhas do milho e posteriores mostraram menor eficácia. Já nos tratamentos com 6 e $9 \mathrm{t} \mathrm{ha}^{-1}$ de palha de nabo, pelas avaliações realizadas aos 14 e 30 DAA, as aplicações feitas no milho com cinco folhas não diferiram estatisticamente do controle realizado quando o milho possuía duas folhas.

Em espécies dicotiledôneas, como picãopreto, com o processo de envelhecimento das células, ocorre a formação da parede secundária, composta de celulose, hemicelulose, lignina, pectina e suberina, que reduz o espaço disponivel no citoplasma, oferecendo barreira à passagem dos herbicidas, explicando, em parte, a dificuldade de controle de plantas daninhas desenvolvidas (Vidal, 2002). Outro fator que pode ter interferido é o fato de, nas aplicações mais tardias, a cultura da soja estar mais desenvolvida, atuando como barreira à passagem do herbicida, diminuindo, assim, a exposição da planta daninha ao herbicida.

Na ausência de controle químico, observase que a presença de palha é um importante fator de controle, especialmente quando em maior quantidade $\left(9 \mathrm{tha}^{-1}\right)$, alcançando níveis de até 69\% de controle para papuã (Figura 1A) e $72 \%$ para picão-preto (Figura 1B). Com $6 \mathrm{t} \mathrm{ha}^{-1}$ de palha, os níveis de controle de plantas daninhas foram de até $61 \%$ para papuã e 59\% para picão-preto.

É possivel que tais resultados sejam também influenciados pela qualidade da palhada, em função da cultura antecessora utilizada, já que, avaliando efeitos da cobertura do solo com palha de cana-de-açúcar sobre a emergência de plantas daninhas, Martins et al. (1999) observaram que para B. pilosa, em comparação à testemunha ( $0 \mathrm{t} \mathrm{ha}^{-1}$ de palha), a cobertura morta nas quantidades de 2 a 6 t ha $^{-1}$ aumentou a emergência das plântulas; nas quantidades de 8 a $10 \mathrm{t} \mathrm{ha}^{-1}$ ela não afetou a emergência; e na quantidade de $15 \mathrm{t} \mathrm{ha}^{-1}$ ela inibiu a emergência de picão-preto.
Em ambos os casos, o controle na testemunha sob pousio foi praticamente inexistente. Solos sem cobertura vegetal apresentam maior amplitude térmica diária do que solos protegidos, estimulando as sementes de plantas daninhas próximas da superfície a germinar, por sofrerem efeito térmico acentuado, passando do estado dormente para quiescente (Salton \& Mielnickzuk, 1995; Theisen et al., 2000). Além disso, a redução da quantidade e modificação da qualidade da luz que atinge as sementes em solos cobertos com palha na superfície poderia explicar a menor densidade de plantas daninhas, especialmente papuã, em solos com cobertura (Theisen et al., 2000).
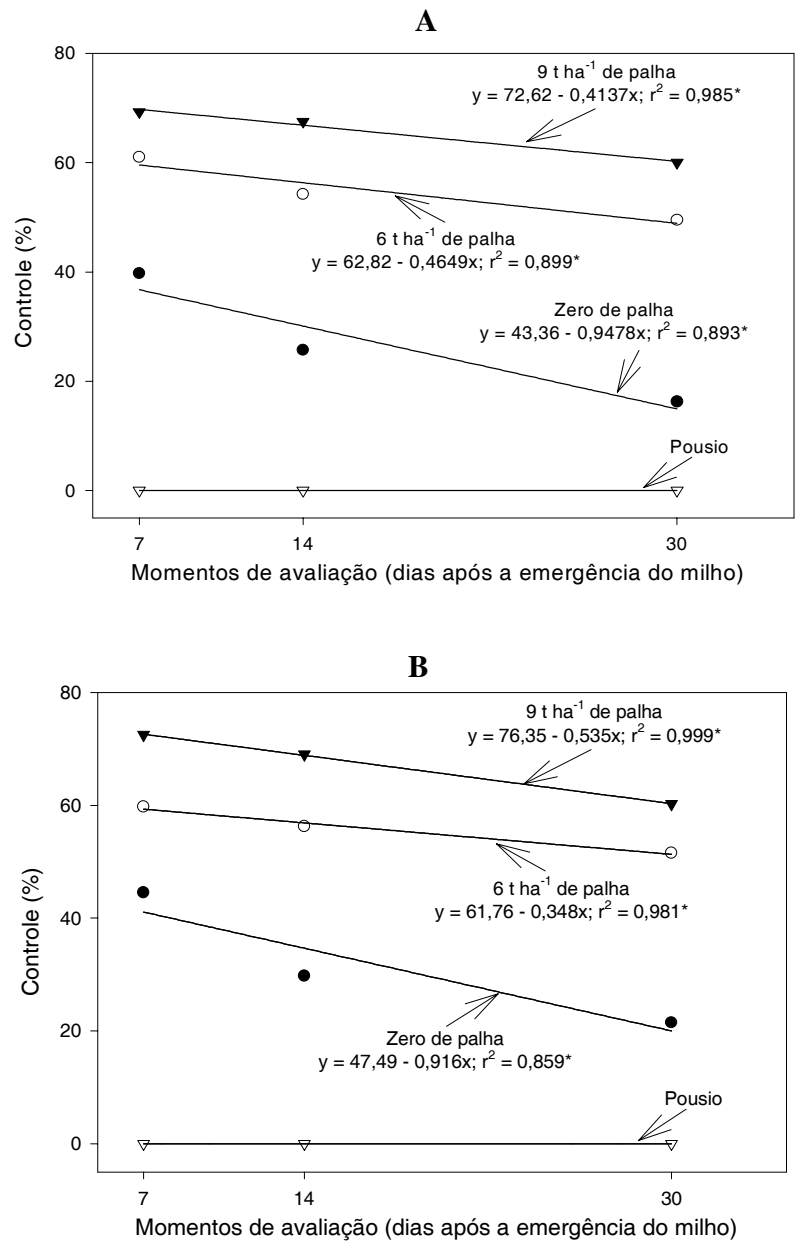

Figura 1 - Efeito da palha de nabo forrageiro no controle de papuã (A) e picão-preto (B) na testemunha sem controle químico, em função de momentos de avaliação. Cepagro/ UPF, Passo Fundo-RS, 2002/2003. 
Em todos os momentos, o tratamento com $9 \mathrm{t} \mathrm{ha}^{-1}$ de palha foi o que apresentou menor número de plantas daninhas emergidas (Figura 2). Observa-se também que, sem a presença de palha, já aos $7 \mathrm{DAE}$, o número de plantas daninhas foi maior que o dobro da quantidade existente nos demais tratamentos, decrescendo progressivamente nos momentos posteriores. Vidal et al. (2004) constataram que a presença de papuã no início do período crítico (20 DAE) de competição pode resultar em perdas de $288 \mathrm{~kg} \mathrm{ha}^{-1}$ do rendimento do milho quando a infestação for de até 24 plantas $\mathrm{m}^{-2} \mathrm{e}$, quando superior, cada planta de papuã foi responsável por perdas de $17 \mathrm{~kg} \mathrm{ha}^{-1}$ no rendimento.

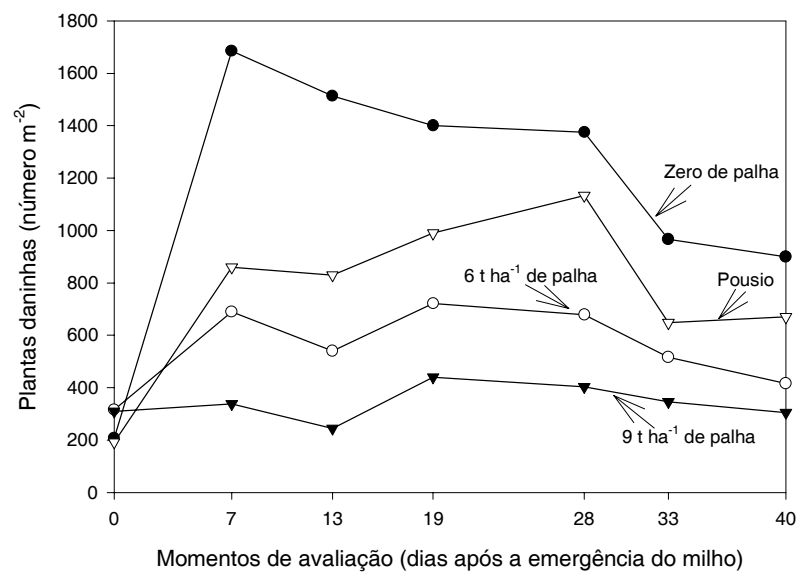

Figura 2 - Número de plantas daninhas emergidas, na testemunha sem controle químico, sob diferentes quantidades de palha de nabo forrageiro. Cepagro/UPF, Passo Fundo-RS, 2002/03.

Nas áreas com a presença de palha, tanto em 6 como em $9 \mathrm{tha}^{-1}$, o número de plantas emergidas nas primeiras contagens foi de 36,1 e $16,1 \%$, respectivamente, em relação ao tratamento sem palha (100\%), aumentando até 28 DAE (milho com cinco folhas) e voltando a decrescer posteriormente.

Com os resultados obtidos, percebe-se que, somente com o efeito da palha, pode-se reduzir substancialmente o número de plantas daninhas emergidas, permitindo também à cultura melhor desenvolvimento inicial pela redução da interferência causada por elas. Nas primeiras semanas após a emergência, o milho intercepta pequena quantidade da radiação luminosa incidente sobre a lavoura, pois sua área foliar ainda é pouco expressiva e a densidade de plantas é insuficiente para cobrir toda a superfície do solo, permitindo que grande quantidade da energia luminosa seja aproveitada pelas plantas daninhas. À medida que a cultura se desenvolve, aumentam a captação da luz e o sombreamento da área, tornando a cultura mais competitiva com as plantas daninhas, especialmente aquelas que emergiram após esse período (Vidal et al., 2004). Essa ocupação, ou captura, dos espaços ocorre, viabilizando somente as plantas mais vigorosas - geralmente as primeiras a emergir (Radosevich et al., 1997).

Para matéria seca das plantas daninhas, no momento do florescimento, somente observaram-se efeitos simples das quantidades de palha e dos momentos de controle das plantas daninhas (Tabela 3). Em relação à quantidade de palha, observa-se que o tratamento sem palha foi o que acumulou maior quantidade de matéria seca de plantas daninhas, porém sem diferir do tratamento com $6 \mathrm{t} \mathrm{ha}^{-1}$ de palha. Por sua vez, 6 e $9 \mathrm{t} \mathrm{ha}^{-1}$ e pousio permitiram acúmulos de matéria seca de plantas daninhas semelhantes entre si.

Tabela 3 - Matéria seca de plantas daninhas $\left(\mathrm{g} \mathrm{m}^{-2}\right)$ coletadas em função das quantidades de palha e dos momentos de controle de plantas daninhas. Cepagro/UPF, Passo FundoRS

\begin{tabular}{|l|c|}
\hline \multicolumn{1}{|c|}{ Quantidade de palha } & Matéria seca $\left(\mathrm{g} \mathrm{m}^{-2}\right)$ \\
\hline Sem palha & $220,00 \mathrm{a}$ \\
\hline $6 \mathrm{t} \mathrm{ha}^{-1}$ & $159,00 \mathrm{ab}$ \\
\hline $9 \mathrm{t} \mathrm{ha}^{-1}$ & $86,00 \mathrm{~b}$ \\
\hline Pousio & $129,00 \mathrm{~b}$ \\
\hline Coeficiente de variação & $70,84 \%$ \\
\hline Momento de controle & Matéria seca $\left(\mathrm{g} \mathrm{m}^{-2}\right)$ \\
\hline Milho com 1 folha & $104 \mathrm{~cd} *$ \\
\hline Milho com 2 folhas & $94 \mathrm{~cd}$ \\
\hline Milho com 4 folhas & $43 \mathrm{~cd}$ \\
\hline Milho com 5 folhas & $74 \mathrm{~cd}$ \\
\hline Milho com 6 folhas & $131 \mathrm{c}$ \\
\hline Milho com 7 folhas & $288 \mathrm{~b}$ \\
\hline Sem erva & $0 \mathrm{~d}$ \\
\hline Sem controle & $454 \mathrm{a}$ \\
\hline Coeficiente de variação & $63,77 \%$ \\
\hline
\end{tabular}

* Médias seguidas da mesma letra não diferem estatisticamente pelo teste de Tukey a $5 \%$ de probabilidade. 
Quanto aos momentos de controle, observa-se que a matéria seca das plantas daninhas não diferiu estatisticamente até o momento em que o milho apresentou cinco folhas, aumentando quando a aplicação do herbicida foi realizada nos momentos posteriores, em razão da menor eficácia dos herbicidas quando as plantas daninhas já estão mais desenvolvidas e, também, da própria barreira física que se forma, tanto pela cultura quanto pelas próprias plantas daninhas.

Os resultados de rendimento de grãos são apresentados na Tabela 4. Para essa variável observou-se interação de quantidades de palha e momentos de controle das plantas daninhas. A análise das quantidades de palha denota que apenas a testemunha sem controle mostra-se diferente das demais. Neste caso, o tratamento com $9 \mathrm{t} \mathrm{ha}^{-1}$ foi superior em rendimento do milho. Esse fato já era esperado, visto que nos demais tratamentos o controle químico tende a igualar os resultados, embora tenham sido encontradas diferenças entre os momentos de controle nos tratamentos sem palha e com $6 \mathrm{t} \mathrm{ha}^{-1}$ de palha. Na cobertura com $9 \mathrm{t} \mathrm{ha}^{-1}$ de palha de nabo forrageiro não houve efeito do herbicida, ou seja, a cobertura morta substituiu o seu efeito. Quando se compara a ausência de cobertura vegetal com tratamentos com algum tipo de cobertura em casos de controle químico insuficiente, a diferença nos resultados é acentuada, indicando a importância do controle cultural exercido pela biomassa vegetal sobre o solo (Pereira \& Scheeren, 2002). Os resultados demonstram que a presença de palha é um importante fator de controle de plantas daninhas.

Quando as plantas daninhas são removidas ou controladas no início do desenvolvimento da cultura, pequena ou nenhuma redução no rendimento resultará pela reinfestação de plantas daninhas (Carey \& Kells, 1995). Por outro lado, o atraso na época de controle fará com que a cultura conviva com elas por maior período de tempo, podendo aumentar as perdas no rendimento (Hall et al., 1992). O controle efetuado precocemente permite que ele seja mais eficaz, porém pode ocorrer novo fluxo de emergência (Mulugeta \& Boerboom, 2000), como ocorrido com picão-preto (Tabela 2). Segundo Gower et al. (2002), reinfestações de plantas daninhas depois da aplicação de herbicidas pós-emergentes em épocas de desenvolvimento inicial da cultura têm menor potencial para reduzir o rendimento do que aplicações tardias, porém resultam em incremento no banco de sementes, podendo ter impacto negativo em culturas subseqüentes. Isso denota a importância da observação do estádio ideal para o controle das plantas daninhas, pois, à medida que a aplicação é atrasada, há menor eficácia de controle, apresentando as plantas maior desenvolvimento vegetativo e tolerância aos herbicidas (Carey \& Kells, 1995).

Tabela 4 - Rendimento de grãos de milho $\left(\mathrm{kg} \mathrm{ha}^{-1}\right)$ em função das quantidades de palha e dos momentos de controle de plantas daninhas. Cepagro/UPF, Passo Fundo-RS, 2002/03

\begin{tabular}{|c|c|c|c|c|c|c|c|c|c|c|c|c|}
\hline \multirow{3}{*}{$\begin{array}{c}\begin{array}{c}\text { Momento de } \\
\text { controle }\end{array} \\
1 \text { folha }\end{array}$} & \multicolumn{9}{|c|}{ Quantidade de palha } & \multirow{2}{*}{\multicolumn{3}{|c|}{ Pousio }} \\
\hline & \multicolumn{3}{|c|}{ Sem palha } & \multicolumn{3}{|c|}{$6 \mathrm{t} \mathrm{ha}^{-1}$} & \multicolumn{3}{|c|}{$9 \mathrm{t} \mathrm{ha}^{-1}$} & & & \\
\hline & A & 8.579 & $a b^{*}$ & A & 9.636 & $a b$ & A & 8.886 & $\mathrm{a}$ & A & 8.656 & $a b$ \\
\hline 2 folhas & A & 9.409 & $\mathrm{a}$ & A & 9.490 & $a b$ & A & 9.072 & $\mathrm{a}$ & A & 8.983 & $a b$ \\
\hline 4 folhas & A & 9.253 & a & A & 10.433 & a & A & 9.315 & $\mathrm{a}$ & A & 8.473 & $a b$ \\
\hline 5 folhas & A & 8.853 & $\mathrm{ab}$ & A & 9.333 & $\mathrm{ab}$ & A & 9.651 & $\mathrm{a}$ & A & 8.207 & $a b$ \\
\hline 6 folhas & A & 8.207 & $\mathrm{ab}$ & A & 9.344 & $a b$ & A & 8.842 & $\mathrm{a}$ & A & 8.116 & $a b$ \\
\hline 7 folhas & A & 7.601 & $\mathrm{ab}$ & A & 8.414 & $\mathrm{ab}$ & A & 9.600 & $\mathrm{a}$ & A & 8.165 & $\mathrm{ab}$ \\
\hline Sem erva & A & 9.717 & a & A & 10.164 & a & A & 8.833 & $\mathrm{a}$ & A & 9.485 & a \\
\hline Sem controle & $\mathrm{B}$ & 5.904 & $\mathrm{~b}$ & $\mathrm{AB}$ & 7.884 & $\mathrm{~b}$ & A & 9.231 & $\mathrm{a}$ & B & 6.766 & $\mathrm{~b}$ \\
\hline
\end{tabular}

Coeficiente de variação: fator quantidades de palha $(14,47 \%)$; fator momentos de controle $(10,78 \%)$

* Médias antecedidas da mesma letra maiúscula na linha, ou sucedidas pela mesma letra minúscula na coluna, não diferem estatisticamente pelo teste de Tukey a $5 \%$ de probabilidade. 
Comparando o acréscimo em rendimento de grãos do milho em função das quantidades de palha e momentos de controle, observa-se que na quantidade zero de palha foi onde o controle químico exerceu maior influência, resultando em maiores rendimentos adicionais (Figura 3). À medida que se aumentam as quantidades de palha, menor efeito tem o controle químico sobre o rendimento de grãos, o que denota a capacidade que a cobertura do solo apresenta na supressão de plantas daninhas. O ganho máximo em rendimento ocorreu aos 20 DAE do milho, com ganhos de 26,3 e $58,7 \%$ com $6 \mathrm{t} \mathrm{ha}^{-1}$ e sem palha de nabo forrageiro, respectivamente.

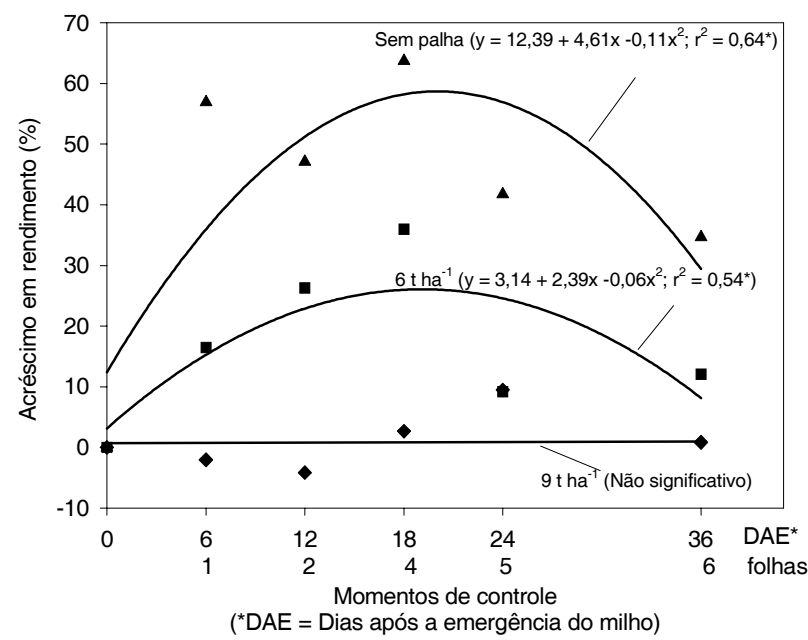

Figura 3 - Acréscimos de rendimento de grãos de milho em função de quantidades de palha de nabo forrageiro e momentos de controle de plantas daninhas. Cepagro/UPF, Passo Fundo-RS, 2002/03.

Portanto, com os resultados obtidos, percebe-se que somente com o efeito da palha pode-se reduzir substancialmente o número de plantas daninhas emergidas, permitindo também à cultura melhor desenvolvimento inicial devido à redução da interferência causada por elas.

\section{LITERATURA CITADA}

CAREY, J. B.; KELLS, J. Timing of total postemergence herbicide applications to maximize weed control and corn (Zea mays) yield. Weed Technol., v. 9, p. 356-361, 1995.
CORREIA, N. M.; DURIGAN, J. C. Emergência de plantas daninhas em solo coberto com palha de cana-de-açúcar. B. Inf. SBCPD, v. 10, 2002. (Suplemento)

FLECK, N. G. et al. Período crítico para controle de Brachiaria plantaginea em função de épocas de semeadura da soja após dessecação da cobertura vegetal. Planta Daninha, v. 20, p. 53-62, 2002.

GOWER, S. A. et al. Effect of planting date, residual herbicide, and postemergence application timing on weed control and grain yield in glyphosate-tolerant corn (Zea mays). Weed Technol., v. 16, p. 488-494, 2002.

HALL, M. R.; SWANTON, C. J.; ANDERSON, G. W. The critical period of weed control in grain corn (Zea mays). Weed Sci., v. 40, p. 441-447, 1992.

KNEZEVIC, S. Z.; WEISE, S. F. SWANTON, C. J. Interference of redroot pigweed (Amaranthus retroflexus) in corn (Zea mays). Weed Sci., v. 42, p. 568-573, 1994.

MARTINS, D. et al. Emergência em campo de dicotiledôneas infestantes em solo coberto com palha de cana-de-açúcar. Planta Daninha, v. 17, p. 151-161, 1999.

MULUGETA, D.; BOERBOOM, C. M. Critical time of weed removal in glyphosat-reistant Glycine max. Weed Sci., v. 48 , p. $35-42,2000$.

PEREIRA, F. A. R.; SCHEEREN, B. Interação do ambiente, fontes de cobertura morta e herbicidas, sobre a dinâmica de plantas daninhas na cultura do milho. B. Inf. SBCPD, v. 10, 2002. (Suplemento).

RADOSEVICH, S. R.; HOLT, J. S.; GHERSA, C. Weed ecology: implications for management. New York: Wiley \& Sons, 1997. 589 p.

SALTON, J.C.; MIELNICZUK, J. Relações entre sistemas de preparo, temperatura e umidade de um Podzólico vermelho-escuro de Eldorado de Sul (RS). R. Bras. Ci. Solo, v. 19, n. 2, p. 313-319, 1995.

THEISEN, G.; VIDAL, R. A.; FLECK, N. G. Redução da infestação de Brachiaria plantaginea em soja pela cobertura do solo com palha de aveia-preta. Pesq. Agropec. Bras., v. 35, p. $753-756,2000$.

VIDAL, R. A. Ação dos herbicidas. Porto Alegre: Edição do autor. 2002. 89 p.

VIDAL, R. A. et al. Nível de dano econômico de Brachiaria plantaginea na cultura de milho irrigado. Planta Daninha, v. 22, p. 63-69, 2004. 